\title{
Phylogenetic and functional diversity of aldehyde-alcohol dehydrogenases in microalgae
}

\author{
Robert van Lis ${ }^{1,2}$, Yohann Couté ${ }^{3}$, Sabine Brugière ${ }^{3}$, Nicolas J. Tourasse ${ }^{4}$, Benoist Laurent ${ }^{5}$, Wolfgang \\ Nitschke ${ }^{1}$, Olivier Vallon ${ }^{4}$ and Ariane Atteia ${ }^{1,6, *}$
}

${ }^{1}$ Aix Marseille Université, CNRS, BIP UMR 7281, Marseille, France

${ }^{2}$ LBE, Univ Montpellier, INRAE, Narbonne, France

${ }^{3}$ Univ Grenoble Alpes, CEA, INSERM, IRIG, BGE, Grenoble, France

${ }^{4}$ UMR7141 CNRS-Sorbonne Université, Institut de Biologie Physico-Chimique, Paris, France ${ }^{5}$ FR 550 CNRS, Institut de Biologie Physico-Chimique, Paris, France ${ }^{6}$ MARBEC, Univ Montpellier, CNRS, Ifremer, IRD, Sète, France.

*Corresponding author: Ariane Atteia

E-mail address: ariane.atteia@cnrs.fr

Present address: MARBEC, Station Ifremer, Avenue Jean Monnet, Sète, France 


\begin{abstract}
Aldehyde-alcohol dehydrogenases (ADHEs) are large metalloenzymes that typically perform the two-step reduction of acetyl-CoA into ethanol. These enzymes consist of an N-terminal acetylating aldehyde dehydrogenase domain (ALDH) and a C-terminal alcohol dehydrogenase (ADH) domain. ADHEs are present in various bacterial phyla as well as in some unicellular eukaryotes. Here we focus on ADHEs in microalgae, a diverse and polyphyletic group of plastid-bearing unicellular eukaryotes. Genome survey shows the uneven distribution of the $A D H E$ gene among free-living algae, and the presence of two distinct genes in various species. We show that the non-photosynthetic Chlorophyte alga Polytomella sp. SAG 198.80 harbors two genes for ADHE-like enzymes with divergent C-terminal ADH domains. Immunoblots indicate that both ADHEs accumulate in Polytomella cells growing aerobically on acetate or ethanol. ADHE1 of $\sim 105-\mathrm{kDa}$ is found in particulate fractions, whereas ADHE2 of $\sim 95-\mathrm{kDa}$ is mostly soluble. The study of the recombinant enzymes revealed that ADHE1 has both the ALDH and ADH activities, while ADHE2 has only the ALDH activity. Phylogeny shows that the divergence occurred close to the root of the Polytomella genus within a clade formed by the majority of the Chlorophyte ADHE sequences, next to the cyanobacterial clade. The potential diversification of function in Polytomella spp. unveiled here likely took place after the loss of photosynthesis. Overall, our study provides a glimpse at the complex evolutionary history of the ADHE in microalgae which includes $i$ ) acquisition via different gene donors, ii) gene duplication and iii) independent evolution of one of the two enzymatic domains.
\end{abstract}

Keywords: Alcohol dehydrogenase (ADH), bifunctional enzyme, gene duplication, Polytomella, spirosome

\title{
Declarations
}

\section{Funding}

This work was supported by the Centre National de la Recherche Scientifique (CNRS), Aix-Marseille Université (AMU) and the LABEX Dynamo (ANR-11-LABX-0011-01). Proteomic experiments were partly supported by the Agence Nationale de la Recherche (ANR-10-INBS-08-01 ProFI grant).

\section{Conflicts of interest}

The authors declare that they have no conflicts of interest with the contents of this article.

Ethics approval (include appropriate approvals or waivers) N/A

Consent to participate (include appropriate statements) N/A

Consent for publication (include appropriate statements) N/A

Availability of data and material (data transparency)

The ADHE1 cDNA sequence can be found in the DDBJ/EMBL/GenBank databases under the accession number PRJEB33479

Code availability (software application or custom code) N/A

\section{Authors' contributions}

AA and RvL conceived the study, designed and conducted the experiments. OV, NJT, BL and AA assembled and annotated genomes. YC and SB performed the proteomic studies. AA, RvL, WN and OV performed the bioinformatics analyses. AA, RvL and $\mathrm{OV}$ wrote the manuscript and generated the figures.

All authors participated and approved the final version of the manuscript. 


\section{Introduction}

Microalgae represent a diverse and polyphyletic group of plastid-bearing unicellular eukaryotes. At the base of aquatic ecosystems, microalgae also contribute significantly to carbon cycling and storage. Deciphering algal genome sequences has shed light on unforeseen metabolic functions and identified targets for genetic manipulations, both for laboratory reference algae such as Thalassiosira pseudonana (Armbrust et al. 2004) and Chlamydomonas reinhardtii (Merchant et al. 2007) and for algae with a biotechnological potential such as Chlorella spp. (Guarnieri et al. 2018; Wu et al. 2019) and Nannochloropsis spp. (Radakovits et al. 2012; Wang et al. 2014). The availability of genomes of less studied algal species (Kim et al. 2014; Nelson et al. 2019; BlabyHaas and Merchant 2019) have greatly helped our understanding of $i$ ) the molecular mechanisms underlying adaptation to adverse ecological niches and ii) the evolutionary history of the different lineages. Among the surprises revealed by algal genome sequencing is the extended repertoire of fermentative enzymes in $C$. reinhardtii (Atteia et al. 2006; Mus et al. 2007). Such a repertoire was long thought to be restricted to prokaryotes and anaerobic protists (Rosenthal et al. 1997; Müller et al. 2012). Multidisciplinary studies have lifted the veil on the significance of these enzymes and their integration in the global metabolism of the photosynthetic alga (Mus et al. 2007; Hemschemeier et al. 2008; Catalanotti et al. 2012; Magneschi et al. 2012; van Lis et al. 2013; van Lis et al. 2017; van Lis et al. 2020).

The aldehyde-alcohol dehydrogenase (ADHE) is one of the enzymes discovered in the green alga $C$. reinhardtii that was thought to be lacking in aerobic eukaryotes. In bacteria and amitochondriate eukaryotes, ADHE is a crucial fermentative enzyme that interconverts acetyl-CoA to ethanol with acetaldehyde as an intermediate (Kessler et al. 1991; Bruchhaus and Tannich 1994; Sánchez 1998). ADHE is a fascinating example of a non-cytoskeleton enzyme that can self-assemble into long filaments. The ability of the ADHE to autoassemble in vivo into large right-handed helices, also named spirosomes, was first described in Lactobacillus (Kawata et al. 1975), and later in Escherichia coli (Kessler et al. 1992) and in the anaerobic protist Entamoeba histolytica (Bruchhaus and Tannich 1994). Recent cryo-electron microscopy studies of E. coli ADHE revealed the mechanism of spirosome formation and highlighted residues critical for oligomerization (Kim et al. 2019; Pony et al. 2020).

The ADHE in the green alga C. reinhardtii resembles its bacterial and eukaryotic counterparts in several aspects: $i)$ it has an $N$-terminal acetylating aldehyde dehydrogenase domain and a $C$-terminal alcohol dehydrogenase domain; $i$ i) it catalyzes the sequential NADH-dependent reductions of acetyl-CoA to acetaldehyde and then to ethanol and iii) has the ability to form spirosomes (van Lis et al. 2017). However, the algal enzyme differs from previously described ADHEs in its intracellular localization, i.e. it is a chloroplast protein, and in its regulation, in particular the fact that it is expressed at ambient oxygen levels and the correlation to starch accumulation (van Lis et al. 2017). In the unicellular alga Polytomella sp. SAG 198.80 (Polytomella sp.), a close relative of C. reinhardtii that lacks photosynthetic pigments and a plastid genome (Pringsheim 1955; Smith and Lee 2014), an ADHE-like protein was also identified (Atteia et al. 2003). However, the enzymatic activities of the protein, which resides in the mitochondrion (Atteia et al. 2003), have never been investigated. Since the discovery of ADHE genes in the Chlorophytes Polytomella and C. reinhardtii, homologous genes have been found in other lineages, including in algae harboring secondary plastids such as the Rhizarian Bigelowiella natans and the Cryptophyte Guillardia theta (Atteia et al. 2013). As in C. reinhardtii and Polytomella sp., the ADHE gene in B. natans and G. theta is expressed at ambient oxygen levels (Gould et al. 2019), unlike in bacteria.

In the course of sequencing the genome of Polytomella sp., we found as expected the ADHE gene whose product has been described earlier as a major mitochondrial protein (Atteia et al. 2003), but also a second gene for a putative ADHE. In this study, we validate the presence of two distinct ADHE-like proteins in the nonphotosynthetic alga, and we provide a comparison of their biochemical and enzymatic characteristics. A genomic and phylogenetic study of $A D H E$ s in unicellular algae reveals novel aspects of the origin and evolution of ADHEs in mitochondriate eukaryotes. 


\section{Results}

\section{Structural features of Polytomella sp. ADHEs inferred by their primary sequences}

The genome sequence of Polytomella sp. revealed, in addition to the previously described ADHE gene (Atteia et al. 2003), another gene for a putative ADHE. For reasons detailed below, we call the newly uncovered gene $A D H E 1$, while the $A D H E$ gene firstly described is renamed $A D H E 2$. The overall primary sequence comparison indicates that $P S A D H E 1$ is 104-aa larger than PsADHE2, but also significantly less related to $P s$ ADHE2 than to its counterpart in the photosynthetic alga $C$. reinhardtii (CrADHE1), sharing respectively $60 \%$ and $72 \%$ amino acid identity. To bring insights into the differences between the ADHEs in the colorless alga, their amino acid sequences were aligned with that of $E$. coli (EcADHE), to date the best studied bacterial ADHE, and that of $C$. reinhardtii, the only algal ADHE characterized so far. The most relevant diverging features are depicted in Fig. 1A. As compared to PsADHE2, PsADHE1 possesses extended $N$ - and $C$-termini. The $C$-terminal extension of PsADHE1 (55-aa) is characterized by a high content in proline and hydroxylated residues (Supplementary Fig. $\mathrm{S} 1$ ). Compared to their homologues in E. coli (and other bacteria), the algal ADHEs have an N-terminal extension, indicative of intracellular targeting. As shown earlier, the 27 -aa $N$-terminus in PsADHE2 serves as a targeting sequence to the mitochondrion (Atteia et al. 2003). This localization is predicted with high confidence by the public software programs MitoFate, TargetP and Predotar (Table 1). In contrast, a plastid localization is predicted by the software Predalgo, designed to predict the intracellular targeting of precursor proteins of C. reinhardtii and other Chlorophytes (Tardif et al. 2012). For PsADHE1, the programs agreed to various extents on a plastid targeting prediction (Table 1). As no adequate protocol to obtain pure fractions of the nonphotosynthetic plastids and mitochondria of the colorless alga is available at present, the plastid localization of ADHE1 remains hypothetical.

The multiple sequence alignment indicates that the ADHEs in Polytomella diverge most in the alcohol dehydrogenase (ADH) domain (Supplementary Fig. S1). While PsADHE1 harbors the two Fe-ADH signature patterns (Prosite ADH_iron_1, PS00913; ADH_iron_2, PS00060), PsADHE2 has a poorly conserved ADH_iron_2 signature, lacking in particular the two histidine residues required for iron coordination (Montella et al. 2005) (Conserved Domains database cd08178). Furthermore, in contrast to PsADHE1, PsADHE2 lacks a few residues identified by cryo-EM as critical for E. coli ADHE auto-assembly (Kim et al. 2019). In particular, the aromatic residue between the two Fe-ADHE signatures (F670 in EcADHE, Y735 in PsADHE1), suggested to be critical for spirosome formation, is replaced by an arginine in PsADHE2 (R699) (Supplementary Fig. S1). The distinct features revealed by sequence analysis warranted a detailed biochemical and enzymatic comparative study of the two Polytomella ADHEs.

\section{Kinetic analysis of recombinant PsADHE1 and PsADHE2}

ADHE typically catalyzes the reversible conversion of acetyl-CoA into ethanol with an acetaldehyde intermediate (Fig. 1C). Four distinct reactions can be assessed in vitro by spectrophotometry measuring the oxidation of NADH or the reduction of $\mathrm{NAD}^{+}$, as shown earlier with the $C$. reinhardtii ADHE (van Lis et al. 2017). To get insights into the respective enzymatic properties of the two Polytomella ADHEs the proteins were produced heterologously in E. coli. Coding sequences lacking the putative targeting sequences were cloned into the pET24a expression vector (primers sequences are given in Supplementary Table S1). A truncated version of PsADHE1 lacking the last 41 residues (Supplementary Fig. S1) was also produced to investigate the significance of the $C$ terminal extension. The recombinant ADHEs were purified via affinity chromatography (Fig. 1B), taking advantage of the hexahistidine (6xHis)-tag introduced at their $C$-terminus by the vector. The ability of each of the three enzymes to catalyze the different reactions $\left(\mathrm{V}_{\max }\right)$ was assessed. The acetaldehyde formed in reaction \#1 is in direct proximity to the $\mathrm{ADH}$ active site and reacts away to ethanol immediately (reaction \#2) since both reactions use NADH, producing NAD in a 1:1 stoichiometry. Therefore, it can be considered that the Vmax measured in presence of acetyl-CoA and NAD represents the combined activities of reaction \#1+2, with half of this value corresponding to the actual Vmax of reaction \#1. Measurement of reaction \#1 alone may be approached 
using EDTA to chelate the Fe of the ADH-moiety and inhibit reaction \#2. However, this approach was not successful in previous studies on the CrADHE and was not attempted here (van Lis et al. 2017).

As shown in Table 2, purified recombinant ADHE1 (rADHE1) catalyzed the NADH-dependent ALDH and ADH reactions (\#1,2) as well as the reverse reactions (\#3,4). Thus, PsADHE1 appears as a genuine bifunctional ADHE. The study of the truncated ADHE1 (rADHE1_t ) did not reveal significant differences with respect to rADHE1 for reactions \#1, 2 and 3 (Table 2). However, the activity of rADHE1_t for reaction\#4 was found to be 2.5 to 3 times higher than that of rADHE1, suggesting a regulatory role in the conversion of acetaldehyde to acetyl-CoA for the $C$-terminal extension. Recombinant ADHE2 (rADHE2) catalyzed the acetaldehyde formation from acetylCoA and NADH (reaction\#1) but failed to form ethanol from acetaldehyde and NADH (reaction\#2). The rate of conversion of acetyl-CoA to acetaldehyde was slightly lower for rADHE2 than RADHE1, with 1.52 and 1.88 $\mathrm{U} / \mathrm{mg}$, respectively. In contrast, the CoA-dependent acetaldehyde oxidation activity (reaction\#4) for rADHE2, of $23 \mathrm{U} / \mathrm{mg}$, was significantly higher than that for rADHE1 of $0.27 \mathrm{U} / \mathrm{mg}$. The high activity measured for the conversion of acetaldehyde into acetyl-CoA by rADHE2 might be related to a specific physiological role (see below). The fact that rADHE2 has no ADH activity was not so surprising in view of the absence of key residues for metal coordination (Fig. 1A).

\section{Blue native (BN) PAGE analysis of recombinant ADHE2}

BN-PAGE is a powerful method to analyze the oligomeric states and associated activities of soluble as well as membrane-bound enzymes (Schägger and von Jagow 1991; Schägger et al. 1994). By applying soluble fractions of Polytomella crude mitochondria on BN-PAGE, the native ADHE2 was previously identified as a dimer of 180 $\mathrm{kDa}$ (Atteia et al. 2003; van Lis et al. 2005). We used this method here to analyze the recombinant ADHE2 of Polytomella with respect to that of $C$. reinhardtii ( $C r$-rADHE1), which was shown to separate in two predominant oligomeric forms, i.e. a dimeric and a tetrameric form, with a NAD-dependent ADH activity (van Lis et al. 2017). As shown in Fig. 2, the migration of rADHE2 is fuzzy with the prevalence of a monomeric and a dimeric form. Unlike with $C r$-rADHE1, none of these rADHE2 forms has the ability to oxidize ethanol (Fig. 2, "ADH activity"), which corroborates the in vitro activity measurements (Table 2). In the light of the recently reported cryo-EM structures (Kim et al. 2019; Pony et al. 2020), it may be possible that the oligomeric ADHE forms identified on BN-PAGE for $C$. reinhardtii correspond to the basic unit (dimer) and the next immediate unit (tetramer) in the spirosome formation. While the dimer formation occurs in a head-to-head arm-crossing fashion independent of the ADH domain, the tetramer results from the hydrophobic interactions between the ADH domains from a dimer in a tail-to-tail manner (Kim et al. 2019). The seeming lack of a tetramer for rADHE2 might be related to the replacement of several residues in the $\mathrm{ADH}$ domain that are key for the interactions, in particular the aromatic residue (F670, E. coli numbering) and the residues which form the hydrophobic pocket (Fig. 1A; Supplemental Fig. S1).

\section{Accumulation of ADHEs in Polytomella sp. cells}

To gain insights into the growth conditions leading to the accumulation of ADHE1 and ADHE2 in the nonphotosynthetic alga, we carried out immunoblot experiments using a polyclonal antibody against bacterial and algal ADHEs (anti-ALDH/ADH). As shown in Fig 5A, this serum detects with comparable signals the two recombinant ADHEs, thereby allowing a relative quantification of the proteins in total cell extracts. We first probed cells grown on ethanol at $\mathrm{pH}$ 6.0, in which ADHE2 was shown earlier to be abundant (Atteia et al. 2003). In these cells, immunoblotting experiments identified two distinct proteins (Fig. 3A). Based on the relative electrophoretic migration of the overexpressed proteins, we assigned the larger protein of $\sim 105-\mathrm{kDa}$ to ADHE1, and the smaller protein of $\sim 95-\mathrm{kDa}$ to ADHE2. Looking at the relative intensities of their signals, it can be concluded that ADHE1 is significantly less abundant than ADHE2. In Polytomella sp. cells grown on acetate at $\mathrm{pH}$ 6.0, the relative abundance between ADHE1 and ADHE2 was found to be comparable to that in ethanol-grown cells (Fig. 3B, lane 2), suggesting that the carbon source has no direct effect on the accumulation of the ADHEs. In extracts from acetate-grown cells, mass spectrometry-based proteomics identified both ADHEs with a large 
number of peptides (Supplementary Table S2). The estimation of the ADHE relative abundances using intensitybased absolute quantification (iBAQ) (Schwanhäusser et al. 2011) is in agreement with ADHE2 being significantly more abundant than ADHE1, with an extracted iBAQ value for ADHE2 more than five times higher than for ADHE1 (Supplementary Table S3). As shown in Fig. 3B, CrADHE1 migrates slightly faster than $P s$ ADHE1. This could indicate that the $C$-terminal extension of PsADHE1 (Fig. 1A) is present, at least partially, in the mature protein. The effect of anoxia on the respective accumulation levels of both ADHE was assessed following a protocol described earlier for C. reinhardtii (van Lis et al. 2017). Data indicate that anoxia has no significant effect on the levels of ADHEs (Supplementary Figure S2). Similar findings were reported for the ADHE of C. reinhardtii (van Lis et al. 2017).

It was reported earlier that PsADHE2 is a soluble protein (Atteia et al. 2003). Fractionation of Polytomella cells after sonication and ultracentrifugation confirmed that ADHE2 is predominantly a soluble protein (Fig. 3B, lane 4). In contrast, ADHE1 is found in the particulate fraction (Fig. 3B, lane 3), where it could be associated with membranes or assembled in spirosomes.

\section{Overview of the distribution of the ADHE genes among microalgae}

The growing availability of sequenced genomes and transcriptomes allowed reassessment of the distribution and evolution of aldehyde-alcohol dehydrogenase genes among microalgae. The unicellular algae surveyed here belong to the supergroup of Archaeplastida, which harbor a primary plastid, as well as to supergroups or clades bearing secondary plastids (SAR, Haptista and Cryptista clades). As shown in Supplementary Table 4, less than half of the species analyzed (20/49) have a gene for a bona fide ADHE, defined here by the presence of two consecutive domains with similarities to ALDH and ADH (Fig. 1A). This is clearly not due to incomplete genome annotation, but reflects the gene loss in most algal clades. As observed in Supplementary Table S4, the majority of the algae harboring an $A D H E$ gene fall within the Chlorophyte division (i.e. green algae) of Archaeplastida, as do Polytomella and C. reinhardtii. In Chlorophyceae and Trebouxiophyceae, the ADHE gene is common although some species seem to lack it. Amid the Mamiellophyceae, the tiniest Chlorophytes known to date (Piganeau et al. 2011), no $A D H E$ gene could be found. In the algae with secondary plastids, a scattered distribution of the gene is observed (Supplementary Table S4). To date, B. natans is the only species with a secondary plastid deriving from a green alga for which the genome sequence is publicly available. In this alga, a genuine $A D H E$ gene is present, as reported earlier (Atteia et al. 2013). As shown in Supplementary Table S4, several species with a plastid deriving from a red alga contain an $A D H E$ gene. This is unexpected as of today the gene for the bifunctional enzyme has not been described in red algae (Rhodophytes) (Supplementary Table S4). Among the eight Stramenopiles surveyed here, the marine diatom Fistulifera solaris is the only one with an ADHE gene (in fact it has two highly related genes). In the genomes of the two free-living chromerids (Alveolates) sequenced to date, Chromera velia and Vitrella brassicaformis, genuine ADHE genes were found. Finally, the survey indicates the absence of an ADHE gene in the Haptista Emiliania huxleyi but its presence in the Cryptista G. theta. If we consider the environment in which the microalgae thrive, it seems that the ADHE gene is more common in freshwater species than in marine species (Supplementary Table S4).

Based on the multiple alignment of 105 eukaryotic and bacterial protein sequences (Supplementary Table S5) and the reconstruction of an unrooted Maximum Likelihood phylogenetic tree (Fig. 4), we found that ADHEs from the most evolved Chlorophyte clades (Trebouxiophyceae, Chlorophyceae) group together, close to the clade of Cyanobacteria. This proximity suggests a vertical inheritance of the ADHE gene in this algal division, including for Polytomella sp. SAG 198.80. The remaining green algal ADHEs sequences, which belong to the other clades (Chlorodendrophyceae, Palmophyllophyceae, Prasinophyceae) are found within a composite eukaryotic group made of sequences from amitochondriate eukaryotes and from the algae B. natans and G. theta, described earlier (van Lis et al. 2017). Within this same group are also found the sequences of the Alveolates C. velia and $V$. brassicaformis. The position of the two ADHE sequences of $F$. solaris in a clade formed by the proteobacterial sequences might indicate gene acquisition by lateral transfer or a contaminant bacterial DNA. 
Our gene survey revealed that half of the algal species (10/19) harbor two distinct ADHE genes

\section{Discussion}

\section{The non-photosynthetic alga Polytomella sp. harbors two enzymes related to bacterial ADHEs}

Aldehyde-alcohol dehydrogenases are bifunctional enzymes long thought to be restricted to Bacteria and eukaryotes devoid of mitochondria, where they play a crucial role in fermentative metabolism (Kessler et al. 1991; Bruchhaus and Tannich 1994; Boxma et al. 2004). The occurrence of ADHE-like proteins in microalgae, which are mitochondriate eukaryotes, was interesting in several respects, especially for their integration in an aerobic metabolic context and their evolutionary origin. We have shown recently that the photosynthetic alga $C$. reinhardtii harbors an ADHE that resembles its bacterial counterparts in $i$ ) the enzymatic activities catalyzed and ii) the ability to oligomerize into spirosomes. The phylogeny pointed to the vertical inheritance of the algal enzyme from a cyanobacterial ancestor (van Lis et al. 2017). With the study of the ADHE-related enzymes in Polytomella sp. SAG 198.80 and other Polytomella species, we disclosed fascinating facets of the evolution of the so-called bifunctional enzyme.

Significant molecular and biochemical data on the oxidative phosphorylation complexes of Polytomella sp. have been obtained over the years that provided further evidence for the phylogenetic relationship of the colorless alga with the green alga C. reinhardtii (Atteia et al. 1997; Funes et al. 2002; van Lis et al. 2005; van Lis et al. 2007). The metabolic routes existing in Polytomella have in contrast been poorly investigated and consequently, the knowledge on their mechanisms underlying highly versatile heterotrophic capacities is scarce (Wise 1955; Wise 1959; Atteia et al. 2000). Through this study we provide insights into the aldehyde/alcohol metabolism unexplored so far in Polytomella species. Based on its sequence similarity to C. reinhardtii ADHE1 (Fig. 1A, Supplementary Fig. S1) and enzymatic activities (Table 2), it seems plausible that Polytomella sp. 
ADHE1 functions in the same way, that is in the ethanolic fermentation fueled by starch glycolysis (Magneschi et al. 2012; van Lis et al. 2017). Although Polytomella sp. ADHE2 shares a number of features with CrADHE1 and bacterial ADHEs, our experimental data clearly show that it is not a typical aldehyde-alcohol dehydrogenase. First of all, PsADHE2 is impaired in ethanol dehydrogenase activity (Table 2; Fig. 2). Furthermore, PsADHE2 is a soluble protein occurring as a dimer (Atteia et al. 2003; van Lis et al. 2005) which likely follows from the lack of the key residues required for spirosome formation (Fig. 1A; Supplemental Fig. S1). The absence of an ADHE2 in $C$. reinhardtii illustrates the fact that making predictions on the metabolic enzymes in Polytomella sp. from $C$. reinhardtii studies may have its limits, and emphasizes the importance de develop studies dedicated to the colorless alga. The ADHE gene duplication and divergence (of function and possibly of cellular localization) in the non-photosynthetic alga might be seen as beneficial for the adaptation to a new lifestyle (Zimorski and Martin 2014; Copley 2020).

To our knowledge, this work is the first report of a full-length ADHE that performs only one of the two typical enzymatic reactions. The presence of such an enzyme in the colorless alga is puzzling and raises questions about its metabolic integration. Indeed, in nature there exist acetylating aldehyde dehydrogenases (AcAldDH) (EC 1.2.1.10) which catalyze the same overall reaction as PsADHE2, that is the interconversion of acetaldehyde and acetyl-CoA using NADH as a co-factor (Burton and Stadtman 1953). These mono-enzymatic proteins of $\sim 45$ $\mathrm{kDa}$ can catalyze the formation of acyl-CoAs, such as the conversion of acetaldehyde to acetyl-CoA in the utilization of ethanolamine by Salmonella typhimurium (Roof and Roth 1992), or the formation of aldehydes in alcohol-producing bacteria such as Clostridium beijerinckii (Toth et al. 1999). The reason for keeping a full-length ADHE with a non-functional alcohol dehydrogenase domain is at present unclear, but it is tempting to propose that ADHE2 bears an as yet unknown additional function. It is worth mentioning here that the ADHE in E. coli was found to act as an ATP-dependent RNA helicase through the associate with the small subunit head domain of the ribosome (Shasmal et al. 2016; Kurylo et al. 2018).

In Polytomella, we found that the relative abundance of the ADHEs is comparable in cells growing on ethanol and on acetate ( $\mathrm{pH}$ 6.0) (Fig. 3), which is not in favor of the involvement of ADHE2 (and ADHE1) in ethanol assimilation. Earlier results on ethanol-growing Polytomella sp. indicated that the $\mathrm{pH}$ of the medium had an impact on the expression and accumulation levels of ADHE2, with high levels at $\mathrm{pH} 6.0$ but much lower at $\mathrm{pH}$ 3.7 (Atteia et al. 2003). The external $\mathrm{pH}$ as a regulatory factor may provide hints as to the connection between ADHE2 and mitochondrial respiration, since it was found that $i$ ) ADHE2 steady-state levels were inversely regulated to those of respiratory complexes I, III, IV and to the levels of cytochrome c, and ii) the respiratory rates were 20-25\% lower in isolated mitochondria from cells grown at $\mathrm{pH} 6.0$ ('high' ADHE2) than from cells grown at pH 3.7 ('low' ADHE2) (Atteia et al. 2000). It may be proposed that a downregulation of OXPHOS activity by the external $\mathrm{pH}$ alters TCA cycle activity necessitating a metabolic rerouting involving reductant and CoA pools, in which ADHE2 has a role to play.

Assuming that native ADHE2 only catalyzes the interconversion of acetyl-CoA and acetaldehyde as is the case for the recombinant enzyme (Table 2), the question arises as to the directionality of the reaction catalyzed in vivo by this mitochondrial protein. At $\mathrm{pH} 6.0$ on acetate or on ethanol, PSADHE2 is very abundant. When functioning in the forward direction (Fig. 1C, reaction \#1), its activity would lead to the production of acetaldehyde from acetyl-CoA. Acetaldehyde is highly toxic for the mitochondrial function, and must be metabolized quickly to prevent damage of proteins and DNA (Cederbaum et al. 1973; Cederbaum et al. 1974). In the case of E. coli ADHE, it is proposed that the acetaldehyde remains sequestered inside the spirosome structure and is converted into ethanol at the inner surface without being released into the cell's cytoplasm (Kim et al. 2019). In mitochondria, acetaldehyde detoxification typically occurs via CoA-independent aldehyde dehydrogenase, and results in the production of NADH and acetate. In the Polytomella sp. genome, seven distinct mon-enzyme ALDH genes were identified, and two of them code for enzymes predicted to reside in the mitochondrion. Setting up tools to follow the accumulation and activity of ALDH enzymes in isolated organelles is required to clarify their role in relation to ADHE2. In the proteomic-based analysis of the acetate-grown cells, no ALDH was identified at levels comparable to those of ADHE2 (Supplementary Table S3). When functioning in the reverse direction (Fig. 1C, reaction \#4), ADHE2 would use acetaldehyde to produce acetyl-CoA, a central metabolite (Pietrocola et al. 2015). It has been shown earlier that Polytomella caeca can use acetaldehyde as 
growth substrate (Wise 1968; Wise 1970), but the assimilation pathway was not described. In bacteria, acetaldehyde is involved in metabolic pathways involving various carbohydrate, lipid, and aromatic compounds (Lees and Jago 1978). In Polytomella sp. ADHE2 may be used to assimilate other C-sources, but a source of acetaldehyde in the mitochondrial matrix must be envisioned. In Polytomella cells grown on acetate or on ethanol, acetaldehyde could be produced in the matrix from ethanol, as in the yeast Saccharomyces cerevisiae, by one of at least nine mono-enzymatic ADH predicted from the Polytomella sp. genome. Ethanol is indeed a good carbon source for growth of Polytomella (Atteia et al. 2000). However, we showed here that ADHE2 is also highly expressed in cells growing on acetate (Fig. 3). Acetate assimilation occurs as in any acetoflagellate via acetylCoA synthase likely in the cytosol. Without a better knowledge of the metabolic enzymes and routes existing in the colorless alga, it is difficult to propose a pathway from cytosolic acetyl-CoA to mitochondrial acetaldehyde. In any case, the abundance of ADHE2 prompts further examination of acetaldehyde as important metabolite in Polytomella. Elucidation of the metabolic integration of the ADHE-like enzyme in the colorless alga will have to rely on the use of large-scale analyses including proteomics and metabolic fluxes but also on biochemical approaches.

\section{Diversity of ADHEs in unicellular plastid-bearing eukaryotes}

The genome survey carried out in this work shows that ADHE is a common enzyme among microalgae. Our phylogenetic tree does not allow a full reconstitution of the deep phylogeny of ADHEs, but does reveal a complex history within Chlorophytes (Archaeplastida supergroup). As illustrated here, there seems to be a tendency for gene duplication and maintenance of bona fide ADHE duplicates among Chlorophytes, especially in the Chlorophyceae and Trebouxiophyceae (Fig. 4, Supplementary Table S4,). Sometimes, diverging evolution of one of the ADHE duplicates can occur as exemplified here with the nonphotosynthetic Polytomella species. Interestingly in these species, most mutations seem to have occurred in the C-terminal with two distinct and nonexclusive outcomes: $i$ ) the loss of ADH activity (mutations of the iron-coordinating residues) and ii) the loss of spirosome formation ability (mutation of the aromatic residue). While the ADHE2 in P. magna, the most ancestral of the Polytomella species (Smith et al. 2013), retains the iron-binding and active site residues of the ancestor, it has lost the key aromatic residue for spirosome formation. We therefore predict that ADHE2 in P. magna, while retaining its capacity for ethanol production/oxidation, will not be found in the particulate fraction but rather as a soluble protein. This raises the question of the potential toxicity of the acetaldehyde produced in the absence of spirosome sequestration. Conversely, P. capuana ADHE2, which conserves the aromatic residue but has lost the residues necessary for ADH activity, is likely to be able to self-assemble. Without the residues for ironcoordination and the aromatic residue for the spirosome formation, the ADHE2 in Polytomella sp. SAG 198.80 and in the species $P$. piriformis and $P$. parva represent the most divergent duplicates.

Since Polytomella sp. is the only alga known to date to harbor a full-length ADHE with a catalyticallydefective ADH domain, it is tempting to correlate this evolution to the loss of photosynthetic activity in some way. However, it is clearly not a prerequisite for loss of photosynthesis, as it has not occurred in P. magna. The different Polytomella species represent different stages of functional adaptation of one of the duplicates, but the link between acquisition of mitochondrial targeting sequence and the loss of ADH activity or ability to autoassemble, and the generalized metabolic consequences of the ADHE2 evolution, remains to be studied.

\section{Concluding remarks}

With the study of ADHEs in the algae C. reinhardtii and Polytomella we just begin to understand the significance of this fascinating multifunctional enzyme amid eukaryotes that thrive in oxic conditions, and to decipher the evolutionary steps since gene acquisition in the Archaeplastida supergroup. The original properties of Polytomella ADHE2 unveiled by this work are likely to serve as an inspiration for enzymatic engineering, since ADHEs are promising protein targets in biotechnological applications in ethanol/butanol production, especially in Clostridium spp. 


\section{Materials and Methods}

\section{Algal strain and growth conditions}

Polytomella strain SAG 198.80 (Polytomella sp.) was obtained from the SAG algal culture collection of the University of Göttingen (http://sagdb.uni-goettingen.de/) and axenized using ampicilline. Polytomella sp. was cultivated either on acetate (MAP medium) or ethanol (MEP medium) in low light at room temperature $\left(24^{\circ} \mathrm{C}\right.$ ) without shaking. Both MAP and MEP culture media contain $35 \mathrm{mM}$ MES (Sigma Aldrich), $0.8 \mathrm{mM} \mathrm{K}_{2} \mathrm{HPO}_{4}, 0.2$ $\mathrm{mM} \mathrm{KH}_{2} \mathrm{PO}_{4}, 7.5 \mathrm{mM} \mathrm{NH}_{4} \mathrm{Cl}, 0.3 \mathrm{mM} \mathrm{CaCl}_{2}, 0.5 \mathrm{mM} \mathrm{MgSO}_{4}$. Oligoelements are present at $1.39 \mu \mathrm{m} \mathrm{ZnSO}_{4}, 0.8$ $\mu \mathrm{M} \mathrm{H}_{3} \mathrm{BO}_{3}, 2.65 \mu \mathrm{M} \mathrm{MnSO}_{4}, 0.74 \mu \mathrm{M} \mathrm{FeCl}_{3}, 0.83 \mu \mathrm{M} \mathrm{NaMoO}_{4}, 0.16 \mu \mathrm{M} \mathrm{CuSO}_{4}, 0.6 \mu \mathrm{M} \mathrm{KI}$. The pH was adjusted to 5.8 with $\mathrm{KOH}$. Thiamine and cyanocobalamin are added to a final concentration of $20 \mu \mathrm{g} / \mathrm{L}$ and 1 $\mu \mathrm{g} / \mathrm{L}$, respectively. In both media, carbon source is added to a final concentration of $30 \mathrm{mM}$. One-liter Erlenmeyer flasks containing $0.2 \mathrm{~L}$ of culture medium were inoculated with $4 \mathrm{~mL}$ of preculture in exponential growth phase. Cells were harvested in their late log phase, after $\sim 3$ days (Atteia et al. 2000).

\section{Cell fractionation and preparation of cell extracts for mass spectrometry}

Acetate-grown cells were harvested $(3,000 \mathrm{x}$ g for $10 \mathrm{~min})$ at $4{ }^{\circ} \mathrm{C}$ and resuspended in HEPES $50 \mathrm{mM}(\mathrm{pH} 7.5)$ supplemented with the protein inhibitors $1 \mathrm{mM}$ amino caproic acid, $0.5 \mathrm{mM}$ benzamidine). Cells were broken by sonication and briefly further centrifuged at $1,500 \mathrm{rpm}$ to remove insoluble material (starch) and unbroken cells. The resulting supernatant was either analyzed directly by mass-spectromtry to identify and evaluate the relative abundance of the algal ADHEs. Alternatively, the supernatant was ultracentrifuged at $4{ }^{\circ} \mathrm{C}(130,000 \mathrm{x} g$ for one hour) to separate the soluble and particulate fractions. The resulting pellet was washed once in HEPES medium (with protease inhibitors).

\section{PAGE analysis, immunodetection of ADHEs, and in-gel activity}

Proteins in whole cells and cell extracts were precipitated by chloroform/methanol (Wessel and Flügge 1984), and then resuspended in $2 \%$ SDS (w/v). Protein concentrations were determined using the bicinchoninic acid Pierce ${ }^{\mathrm{TM}}$ Protein assay kit (ThermoFisher) using bovine serum albumin as standard. For SDS-PAGE analysis, protein samples $(40 \mu \mathrm{g})$ were resuspended in $2 \% \operatorname{SDS}(\mathrm{w} / \mathrm{v})$ and $2 \%$ beta-mercaptoethanol, and boiled for 90 sec. Insoluble material was removed via a 2 min-centrifugation at 13,000 x g. Apparent molecular masses were estimated using Prestained protein ladder Plus (Euromedex). After electrophoresis, proteins were stained with Coomassie Brillant Blue R250 or transferred onto nitrocellulose membranes (GE Healthcare,) and stained with Ponceau S. Immunoblotting was carried out as described (van Lis et al. 2017). The anti-ADH/ALDH (Agrisera) was used at $1 / 1,000$.

Blue Native-PAGE was carried out using a 3-12\% linear polyacrylamide gradient as described (van Lis et al. 2017). The molecular mass of the rADHE oligomers were estimated using NativeMark ${ }^{\text {TMUnstained Protein }}$ Standard (Thermofisher Scientific). Recombinant CrADHE, used as control protein, was prepared as described previously (van Lis et al. 2017). For ADH activity, BN-gel was washed twice in $100 \mathrm{mM}$ Tris (pH 8.8) and then incubated in $25 \mathrm{ml}$ of $100 \mathrm{mM}$ Tris- $\mathrm{Cl}$ (pH 8.8) containing $20 \mathrm{mg}$ of NAD, $5 \mathrm{mg}$ of nitroblue tetrazolium, $1 \mathrm{mg}$ of phenazine methosulfate, and $25 \mu \mathrm{l}$ of absolute ethanol.

\section{Mass spectrometry-based proteomics}

Protein extract from acetate-grown cells was stacked in the top of a 10\% SDS-PAGE gel and stained with Coomassie Brilliant blue. The band was excised and submitted to in-gel digestion using modified trypsin 
(sequencing grade) (Promega) as previously described (Salvetti et al. 2016). Resulting peptides were analyzed by online nanoliquid chromatography coupled to tandem MS (UltiMate 3000 and LTQ-Orbitrap Velos Pro, Thermo Scientific). Peptides were sampled on a $300 \mu \mathrm{m}$ x $5 \mathrm{~mm}$ PepMap C18 precolumn and separated on a $75 \mu \mathrm{m} \times 250$ mm PepMap C18 column (Thermo Scientific) using a 25-min gradient for individual gel bands and a 80-min gradient for mitochondrial soluble fraction. MS and MS/MS data were acquired using Xcalibur (Thermo Scientific). Peptides and proteins were identified using Mascot (version 2.6) through concomitant searches against homemade Polytomella protein sequence database, classical contaminants sequence database and the corresponding reversed databases. The Proline software (http://proline.profiproteomics.fr) was used to filter the results: conservation of rank 1 peptides, peptide length $\geq 7$ amino acids, false discovery rate of peptide-spectrum matches $<1 \%$ as calculated on scores by employing the reverse database strategy, minimum peptide-spectrum match score of 25, and minimum of 1 specific peptide per identified protein group. Proline was then used to perform a MS1-based label-free quantification of the protein groups identified in the sample.

\section{Polytomella sp. ADHE gene cloning, expression and purification of recombinant enzymes}

Via rapid cDNA amplification-based techniques, both full-length coding sequences were cloned. In brief, total RNA was isolated from acetate-grown cells using the RNeasy Plant Mini Kit (Qiagen, Hilden, Germany). Complementary DNA (cDNA) amplifications were done using the FirstChoice ${ }^{\circledR}$ RLM-RACE Kit (Thermo Fisher Scientific) and specific primers designed based on the Polytomella draft genome sequence. Using the 3' RACE DNAs as templates, the full-length sequences coding Polytomella ADHEs were amplified by PCR using Pfu polymerase (Promega). The primers used to amplify ADHE1 cDNA (2973 bp) and ADHE2 cDNA (2717 bp) are listed in Supplementary Table S1. Sequencing of PsADHE2 cDNAs revealed a few differences with the nucleotide sequence published earlier (Atteia et al. 2003), which are believed to result from an inappropriate assembly of partial cDNA sequences.

The full-length cDNAs were used as templates to amplify the coding sequence for predicted mature proteins using the primers listed in Supplementary Table S1. Amplified fragments were cloned into the pET-24a expression vector (Merck Novagen) using the NdeI and XhoI restriction site within the multiple cloning site to incorporate a 6xHis tag at the C-terminus of the proteins. Constructs with confirmed nucleotide sequences (at GATC Biotech) were used to transform Escherichia coli BL21 (DE3). Transformed cells from plates were inoculated in the autoinduction medium ZYM5052 (Studier 2005) supplemented with kanamycin $(30 \mu \mathrm{g} / \mathrm{ml}$ ), and grown overnight either at $25^{\circ} \mathrm{C}$ for rADHE1, or at $37^{\circ} \mathrm{C}$ for rADHE2. The cells were harvested by centrifugation, washed once in Buffer $2(300 \mathrm{mM} \mathrm{NaCl}, 50 \mathrm{mM}$ sodium phosphate, $\mathrm{pH} 8.0)$ and flash-frozen and stored at $-20^{\circ} \mathrm{C}$ until use. Protein purification was carried out at $4^{\circ} \mathrm{C}$ as follows. Cell pellets were resuspended in Buffer 1 supplemented with 0.5 $\mathrm{mg} / \mathrm{ml}$ lysozyme, $0.5 \mathrm{mg} / \mathrm{ml}$ DNase and $2 \mathrm{mM} \mathrm{MgCl}$, and protease inhibitors (PMSF, amino caproic acid, benzamidine) and subjected to three cycles of freezing (liquid nitrogen) and thawing. The lysates were clarified via centrifugation $\left(10,000 \mathrm{x} g\right.$ for $15 \mathrm{~min}$, at $\left.4^{\circ} \mathrm{C}\right)$ and the supernatant was gently mixed with HIS-Select Nickel Affinity gel (Sigma-Aldrich) equilibrated with Buffer 2 . The mixture was poured into an empty column, and the gel was extensively washed with $20 \mathrm{mM}$ imidazole in Buffer 2. His-tagged ADHEs were eluted with $100 \mathrm{mM}$ imidazole in Buffer 2 rapidly desalted on PD10 Desalting columns (GE Healthcare) pre-equilibrated with $50 \mathrm{mM}$ Tricine, $\mathrm{pH}$ 8.0, and finally concentrated on a Vivaspin 50 (Sartorius) to reach a final concentration of 5-7 mg $\operatorname{protein} / \mathrm{ml}$.

\section{Enzyme assays}

Freshly purified recombinant ADHEs were assessed for the different enzymatic activities at $25^{\circ} \mathrm{C}$. Standard assay medium for NADH-dependent reactions consisted of $50 \mathrm{mM}$ potassium phosphate (pH 7.0) and $0.42 \mathrm{mM} \mathrm{NADH}$. Acetyl-CoA reductase activity was determined in the presence of $0.21 \mathrm{mM}$ acetyl-CoA, acetaldehyde reductase activity with $1 \mathrm{mM}$ acetaldehyde and $0.21 \mathrm{mM} \mathrm{CoASH}$. The rates of both reductase reactions were monitored spectrophotometrically following the disappearance of NADH at $340 \mathrm{~nm}$. Standard assay medium for $\mathrm{NAD}^{+}-$ dependent reactions contained $1.5 \mathrm{mM} \mathrm{NAD}^{+}$in $50 \mathrm{mM}$ Glycine/NaOH buffer $\mathrm{pH}$ 9.0. Ethanol dehydrogenase 
activity was assayed in $170 \mathrm{mM}$ ethanol $(1 \% \mathrm{v} / \mathrm{v})$; acetaldehyde dehydrogenase activity was assayed in $1 \mathrm{mM}$ acetaldehyde and $0.2 \mathrm{mM} \mathrm{CoASH}$. The rates of both dehydrogenases were monitored by the formation of NADH at $340 \mathrm{~nm}$. All reactions were initiated by the addition of purified recombinant enzyme $(25-40 \mu \mathrm{g})$. In all the assays, one unit of enzyme activity (U) was defined as $1 \mu$ mol of NADH (or NAD) converted per min.

\section{Bioinformatic analysis}

The genome of Polytomella sp. SAG 198.80 was assembled from paired-end Illumina and PacBio sequences, using a combination of the programs ABYSS (1.9.0), CERULEAN (0.1), PBJELLY (15.2.20) and BESST (2.1). Details will be published elsewhere. Ab initio annotation was performed with AUGUSTUS, using available transcriptome assemblies to generate the species models. Protein sequences were aligned using MAFFT (7.130) or Clustal Omega 1.2.4. (https://www.ebi.ac.uk/Tools/msa/clustalo/). Enzyme domain searches were done at https://www.ncbi.nlm.nih.gov/Structure/cdd/cdd.shtml. The iron-containing alcohol dehydrogenases signatures (ADH_iron_1, PS00913; ADH_iron_2, PS00060) were obtained at Prosite (https://prosite.expasy.org/) (Bairoch 1992). Intracellular targeting predictions were made using TargetP (Plant network v2.0) (Emanuelsson et al. 2000), Mitofates (plant) v1 (Fukasawa et al. 2015), Predotar (Small et al. 2004) and Predalgo (Tardif et al. 2012).

\section{Phylogenetic dataset construction and analysis}

ADHE proteins sequences were searched among microalgae via BLASTP using the C. reinhardtii ADHE sequence (UniprotKB entry Q1RS84_CHLRE) as a query against the proteomes available at the US National Center for Biotechnology and Information (NCBI) (https://blast.ncbi.nlm.nih.gov/Blast.cgi), at Algoblast (https://giavap-genomes.ibpc.fr/cgi-bin/AlgoBLAST/algoBlast_mainpage.php), at CryptoDB (https://cryptodb.org/cryptodb/), at the Joint Genome Institute (JGI) genome Portal (https://genome.jgi.doe.gov/portal/), and at Phytozome from the JGI (https://phytozome.jgi.doe.gov/). All the retrieved sequences were checked manually for the length and the presence of the key residues and domains of ADHE. A total of 49 algal genome sequences were surveyed. Phylogenetic analyses were conducted using MEGAX and MEGA7 software (http://www.megasoftware.net), and phylogenetic relationships were inferred using the maximum likelihood (ML) method applied with the JTT amino-acid substitution matrix-based model (Jones et al. 1992).

\section{Nucleotide sequence accession numbers}

The ADHE1 cDNA sequence can be found in the DDBJ/EMBL/GenBank databases under the accession number PRJEB33479. The sequence of ADHE2 cDNA (UniProtKB entry- Q70YJ9) has been updated.

\section{Acknowledgements}

This work was supported by the Centre National de la Recherche Scientifique (CNRS), Aix-Marseille Université (AMU) and the LABEX Dynamo (ANR-11-LABX-0011-01). Proteomic experiments were partly supported by the Agence Nationale de la Recherche (ANR-10-INBS-08-01 ProFI grant).

We thank Dr. David R. Smith (Dalhousie University, Canada) for sharing genome assemblies of $P$. magna, $P$. capuana, $P$. piriformis and P. parva.

\section{Reference list}

Armbrust EV, Berges JA, Bowler C, Green BR, Martinez D, Putnam NH, Zhou S, Allen AE, Apt KE, Bechner M, Brzezinski MA, Chaal BK, Chiovitti A, Davis AK, Demarest MS, Detter JC, Glavina T, Goodstein D, Hadi MZ, Hellsten U, Hildebrand M, Jenkins BD, Jurka J, Kapitonov V V, Kröger N, Lau WWY, Lane TW, Larimer FW, Lippmeier JC, Lucas S, Medina M, Montsant A, Obornik M, Parker MS, Palenik B, Pazour GJ, Richardson PM, Rynearson TA, Saito MA, Schwartz DC, Thamatrakoln K, Valentin K, Vardi 
A, Wilkerson FP, Rokhsar DS (2004) The genome of the diatom Thalassiosira pseudonana: ecology, evolution, and metabolism. Science 306:79-86 . https://doi.org/10.1126/science.1101156

Atteia A, Dreyfus G, González-Halphen D (1997) Characterization of the alpha and beta-subunits of the F0F1ATPase from the alga Polytomella spp., a colorless relative of Chlamydomonas reinhardtii. Biochim Biophys Acta 1320:275-284 . https://doi.org/10.1016/s0005-2728(97)00031-5

Atteia A, van Lis R, Gelius-Dietrich G, Adrait A, Garin J, Joyard J, Rolland N, Martin W (2006) Pyruvate formate-lyase and a novel route of eukaryotic ATP synthesis in Chlamydomonas mitochondria. J Biol Chem 281:9909-9918 . https://doi.org/10.1074/jbc.M507862200

Atteia A, van Lis R, Mendoza-Hernández G, Henze K, Martin W, Riveros-Rosas H, González-Halphen D (2003) Bifunctional aldehyde/alcohol dehydrogenase (ADHE) in chlorophyte algal mitochondria. Plant Mol Biol 53:175-188 . https://doi.org/10.1023/B:PLAN.0000009274.19340.36

Atteia A, van Lis R, Ramírez J, González-Halphen D (2000) Polytomella spp. growth on ethanol. Extracellular $\mathrm{pH}$ affects the accumulation of mitochondrial cytochrome c550. Eur J Biochem 267:2850-2858 . https://doi.org/10.1046/j.1432-1327.2000.01288.x

Atteia A, van Lis R, Tielens AGM, Martin WF (2013) Anaerobic energy metabolism in unicellular photosynthetic eukaryotes. Biochim Biophys Acta - Bioenerg 1827:210-223 . https://doi.org/10.1016/j.bbabio.2012.08.002

Bairoch A (1992) Prosite: a dictionary of sites and patterns in proteins. Nucleic Acids Res 20:2013-2018 . https://doi.org/10.1093/nar/20.suppl.2013

Blaby-Haas CE, Merchant SS (2019) Comparative and Functional Algal Genomics. Annu Rev Plant Biol 70:605-638 . https://doi.org/10.1146/annurev-arplant-050718-095841

Boxma B, Voncken F, Jannink S, van Alen T, Akhmanova A, van Weelden SWH, van Hellemond JJ, Ricard G, Huynen M, Tielens AGM, Hackstein JHP (2004) The anaerobic chytridiomycete fungus Piromyces sp. E2 produces ethanol via pyruvate:formate lyase and an alcohol dehydrogenase E. Mol Microbiol 51:13891399 . https://doi.org/10.1046/j.1365-2958.2003.03912.x

Bruchhaus I, Tannich E (1994) Purification and molecular characterization of the NAD(+)-dependent acetaldehyde/alcohol dehydrogenase from Entamoeba histolytica. Biochem J 303 ( Pt 3:743-748 . https://doi.org/10.1042/bj3030743

Burton RM, Stadtman ER (1953) The oxidation of acetaldehyde to acetyl coenzyme A. J Biol Chem 202:873890

Catalanotti C, Dubini A, Subramanian V, Yang W, Magneschi L, Mus F, Seibert M, Posewitz MC, Grossman AR (2012) Altered fermentative metabolism in Chlamydomonas reinhardtii mutants lacking pyruvate formate lyase and both pyruvate formate lyase and alcohol dehydrogenase. Plant Cell 24:692-707 . https://doi.org/10.1105/tpc.111.093146

Cederbaum AI, Lieber CS, Rubin E (1973) Effect of acetaldehyde on activity of shuttles for the transport of reducing equivalents into the mitochondria. FEBS Lett 37:89-92 . https://doi.org/10.1016/00145793(73)80432-6

Cederbaum AI, Lieber CS, Rubin E (1974) The effect of acetaldehyde on mitochondrial function. Arch Biochem Biophys 161:26-39 . https://doi.org/https://doi.org/10.1016/0003-9861(74)90231-8

Copley SD (2020) Evolution of new enzymes by gene duplication and divergence. FEBS J 287:1262-1283 . https://doi.org/10.1111/febs.15299

Emanuelsson O, Nielsen H, Brunak S, von Heijne G (2000) Predicting subcellular localization of proteins based on their N-terminal amino acid sequence. J Mol Biol 300:1005-1016 . https://doi.org/10.1006/jmbi.2000.3903

Fukasawa Y, Tsuji J, Fu S-C, Tomii K, Horton P, Imai K (2015) MitoFates: improved prediction of mitochondrial targeting sequences and their cleavage sites. Mol Cell Proteomics 14:1113-1126 . https://doi.org/10.1074/mcp.M114.043083

Funes S, Davidson E, Gonzalo Claros M, van Lis R, Pérez-Martínez X, Vázquez-Acevedo M, King MP, González-Halphen D (2002) The typically mitochondrial DNA-encoded ATP6 subunit of the F 1 F 0 - 
ATPase is encoded by a nuclear gene in Chlamydomonas reinhardtii. J Biol Chem 277:6051-6058 . https://doi.org/10.1074/jbc.M109993200

Gould SB, Garg SG, Handrich M, Nelson-Sathi S, Gruenheit N, Tielens AGM, Martin WF (2019) Adaptation to life on land at high $\mathrm{O}(2)$ via transition from ferredoxin-to NADH-dependent redox balance. Proceedings Biol Sci 286:20191491 . https://doi.org/10.1098/rspb.2019.1491

Guarnieri MT, Levering J, Henard CA, Boore JL, Betenbaugh MJ, Zengler K, Knoshaug EP (2018) Genome Sequence of the Oleaginous Green Alga, Chlorella vulgaris UTEX 395. Front Bioeng Biotechnol 6:37 . https://doi.org/10.3389/fbioe.2018.00037

Hemschemeier A, Jacobs J, Happe T (2008) Biochemical and Physiological Characterization of the Pyruvate Formate-Lyase Pfl1 of Chlamydomonas reinhardtii, a Typically Bacterial Enzyme in a Eukaryotic Alga $\square .7: 518-526$. https://doi.org/10.1128/EC.00368-07

Jones DT, Taylor WR, Thornton JM (1992) The rapid generation of mutation data matrices from protein sequences. Bioinformatics 8:275-282 . https://doi.org/10.1093/bioinformatics/8.3.275

Kawata T, Masuda K, Yoshino K (1975) Presence of fine spirals (spirosomes) in Lactobacillus fermenti and Lactobacillus casei. Jpn J Microbiol 19:225-227 . https://doi.org/10.1111/j.1348-0421.1975.tb00872.x

Kessler D, Herth W, Knappe J (1992) Ultrastructure and pyruvate formate-lyase radical quenching property of the multienzymic AdhE protein of Escherichia coli. J Biol Chem 267:18073-18079

Kessler D, Leibrecht I, Knappe J (1991) Pyruvate-formate-lyase-deactivase and acetyl-CoA reductase activities of Escherichia coli reside on a polymeric protein particle encoded by adhE. FEBS Lett 281:59-63 . https://doi.org/10.1016/0014-5793(91)80358-a

Kim G, Azmi L, Jang S, Jung T, Hebert H, Roe AJ, Byron O, Song J-J (2019) Aldehyde-alcohol dehydrogenase forms a high-order spirosome architecture critical for its activity. Nat Commun 10:4527 . https://doi.org/10.1038/s41467-019-12427-8

Kim KM, Park J-H, Bhattacharya D, Yoon HS (2014) Applications of next-generation sequencing to unravelling the evolutionary history of algae. Int J Syst Evol Microbiol 64:333-345 . https://doi.org/10.1099/ijs.0.054221-0

Kurylo CM, Parks MM, Juette MF, Zinshteyn B, Altman RB, Thibado JK, Vincent CT, Blanchard SC (2018) Endogenous rRNA Sequence Variation Can Regulate Stress Response Gene Expression and Phenotype. Cell Rep 25:236-248.e6 . https://doi.org/10.1016/j.celrep.2018.08.093

Lees GJ, Jago GR (1978) Role of Acetaldehyde in Metabolism: A Review 1. Enzymes Catalyzing Reactions Involving Acetaldehyde. J Dairy Sci 61:1205-1215 . https://doi.org/https://doi.org/10.3168/jds.S00220302(78)83708-4

Magneschi L, Catalanotti C, Subramanian V, Dubini A, Yang W, Mus F, Posewitz MC, Seibert M, Perata P, Grossman AR (2012) A mutant in the ADH1 gene of Chlamydomonas reinhardtii elicits metabolic restructuring during anaerobiosis. Plant Physiol 158:1293-1305 . https://doi.org/10.1104/pp.111.191569

Merchant SS, Prochnik SE, Vallon O, Harris EH, Karpowicz SJ, Witman GB, Terry A, Salamov A, Fritz-Laylin LK, Maréchal-Drouard L, Marshall WF, Qu LH, Nelson DR, Sanderfoot AA, Spalding MH, Kapitonov V V., Ren Q, Ferris P, Lindquist E, Shapiro H, Lucas SM, Grimwood J, Schmutz J, Grigoriev I V., Rokhsar DS, Grossman AR, Cardol P, Cerutti H, Chanfreau G, Chen CL, Cognat V, Croft MT, Dent R, Dutcher S, Fernández E, Fukuzawa H, González-Ballester D, González-Halphen D, Hallmann A, Hanikenne M, Hippler M, Inwood W, Jabbari K, Kalanon M, Kuras R, Lefebvre PA, Lemaire SD, Lobanov A V., Lohr M, Manuell A, Meier I, Mets L, Mittag M, Mittelmeier T, Moroney J V., Moseley J, Napoli C, Nedelcu AM, Niyogi K, Novoselov S V., Paulsen IT, Pazour G, Purton S, Ral JP, Riaño-Pachón DM, Riekhof W, Rymarquis L, Schroda M, Stern D, Umen J, Willows R, Wilson N, Zimmer SL, Allmer J, Balk J, Bisova K, Chen CJ, Elias M, Gendler K, Hauser C, Lamb MR, Ledford H, Long JC, Minagawa J, Page MD, Pan J, Pootakham W, Roje S, Rose A, Stahlberg E, Terauchi AM, Yang P, Ball S, Bowler C, Dieckmann CL, Gladyshev VN, Green P, Jorgensen R, Mayfield S, Mueller-Roeber B, Rajamani S, Sayre RT, Brokstein P, Dubchak I, Goodstein D, Hornick L, Huang YW, Jhaveri J, Luo Y, Martínez D, Ngau WCA, Otillar B, Poliakov A, Porter A, Szajkowski L, Werner G, Zhou K (2007) The Chlamydomonas genome reveals the evolution of key animal and plant functions. Science (80- ) 318:245-251 .

https://doi.org/10.1126/science.1143609 
Montella C, Bellsolell L, Pérez-Luque R, Badía J, Baldoma L, Coll M, Aguilar J (2005) Crystal structure of an iron-dependent group III dehydrogenase that interconverts L-lactaldehyde and L-1,2-propanediol in Escherichia coli. J Bacteriol 187:4957-4966 . https://doi.org/10.1128/JB.187.14.4957-4966.2005

Müller M, Mentel M, van Hellemond JJ, Henze K, Woehle C, Gould SB, Yu R-Y, van der Giezen M, Tielens AGM, Martin WF (2012) Biochemistry and evolution of anaerobic energy metabolism in eukaryotes. Microbiol Mol Biol Rev 76:444-495 . https://doi.org/10.1128/MMBR.05024-11

Mus F, Dubini A, Seibert M, Posewitz MC, Grossman AR (2007) Anaerobic acclimation in Chlamydomonas reinhardtii: anoxic gene expression, hydrogenase induction, and metabolic pathways. J Biol Chem 282:25475-25486 . https://doi.org/10.1074/jbc.M701415200

Nelson DR, Chaiboonchoe A, Fu W, Hazzouri KM, Huang Z, Jaiswal A, Daakour S, Mystikou A, Arnoux M, Sultana M, Salehi-Ashtiani K (2019) Potential for Heightened Sulfur-Metabolic Capacity in Coastal Subtropical Microalgae. iScience 11:450-465 . https://doi.org/10.1016/j.isci.2018.12.035

Pietrocola F, Galluzzi L, Bravo-San Pedro JM, Madeo F, Kroemer G (2015) Acetyl coenzyme A: a central metabolite and second messenger. Cell Metab 21:805-821 . https://doi.org/10.1016/j.cmet.2015.05.014

Piganeau G, Grimsley N, Moreau H (2011) Genome diversity in the smallest marine photosynthetic eukaryotes. Res Microbiol 162:570-577 . https://doi.org/10.1016/j.resmic.2011.04.005

Pony P, Rapisarda C, Terradot L, Marza E, Fronzes R (2020) Filamentation of the bacterial bi-functional alcohol/aldehyde dehydrogenase AdhE is essential for substrate channeling and enzymatic regulation. Nat Commun 11:1426 . https://doi.org/10.1038/s41467-020-15214-y

Pringsheim EG (1955) The Genus Polytomella*. J Protozool 2:137-145 . https://doi.org/10.1111/j.15507408.1955.tb02413.x

Radakovits R, Jinkerson RE, Fuerstenberg SI, Tae H, Settlage RE, Boore JL, Posewitz MC (2012) Draft genome sequence and genetic transformation of the oleaginous alga Nannochloropis gaditana. Nat Commun 3:686 . https://doi.org/10.1038/ncomms1688

Roof DM, Roth JR (1992) Autogenous regulation of ethanolamine utilization by a transcriptional activator of the eut operon in Salmonella typhimurium. J Bacteriol 174:6634-6643 . https://doi.org/10.1128/jb.174.20.6634-6643.1992

Rosenthal B, Mai Z, Caplivski D, Ghosh S, de la Vega H, Graf T, Samuelson J (1997) Evidence for the bacterial origin of genes encoding fermentation enzymes of the amitochondriate protozoan parasite Entamoeba histolytica. J Bacteriol 179:3736-3745 . https://doi.org/10.1128/jb.179.11.3736-3745.1997

Salvetti A, Couté Y, Epstein A, Arata L, Kraut A, Navratil V, Bouvet P, Greco A (2016) Nuclear Functions of Nucleolin through Global Proteomics and Interactomic Approaches. J Proteome Res 15:1659-1669 . https://doi.org/10.1021/acs.jproteome.6b00126

Sánchez LB (1998) Aldehyde dehydrogenase (CoA-acetylating) and the mechanism of ethanol formation in the amitochondriate protist, Giardia lamblia. Arch Biochem Biophys 354:57-64 . https://doi.org/10.1006/abbi.1998.0664

Schägger H, Cramer WA, von Jagow G (1994) Analysis of molecular masses and oligomeric states of protein complexes by blue native electrophoresis and isolation of membrane protein complexes by twodimensional native electrophoresis. Anal Biochem 217:220-230 . https://doi.org/10.1006/abio.1994.1112

Schägger H, von Jagow G (1991) Blue native electrophoresis for isolation of membrane protein complexes in enzymatically active form. Anal Biochem 199:223-231 . https://doi.org/10.1016/0003-2697(91)90094-a

Schwanhäusser B, Busse D, Li N, Dittmar G, Schuchhardt J, Wolf J, Chen W, Selbach M (2011) Global quantification of mammalian gene expression control. Nature 473:337-342 . https://doi.org/10.1038/nature10098

Shasmal M, Dey S, Shaikh TR, Bhakta S, Sengupta J (2016) E. coli metabolic protein aldehyde-alcohol dehydrogenase-E binds to the ribosome: a unique moonlighting action revealed. Sci Rep 6:19936 . https://doi.org/10.1038/srep19936

Small I, Peeters N, Legeai F, Lurin C (2004) Predotar: A tool for rapidly screening proteomes for N-terminal targeting sequences. Proteomics 4:1581-1590 . https://doi.org/10.1002/pmic.200300776 
Smith DR, Hua J, Archibald JM, Lee RW (2013) Palindromic genes in the linear mitochondrial genome of the nonphotosynthetic green alga Polytomella magna. Genome Biol Evol 5:1661-1667 . https://doi.org/10.1093/gbe/evt122

Smith DR, Lee RW (2014) A plastid without a genome: evidence from the nonphotosynthetic green algal genus Polytomella. Plant Physiol 164:1812-1819 . https://doi.org/10.1104/pp.113.233718

Studier FW (2005) Protein production by auto-induction in high density shaking cultures. Protein Expr Purif 41:207-234 . https://doi.org/10.1016/j.pep.2005.01.016

Tardif M, Atteia A, Specht M, Cogne G, Rolland N, Brugière S, Hippler M, Ferro M, Bruley C, Peltier G, Vallon O, Cournac L (2012) PredAlgo: A New Subcellular Localization Prediction Tool Dedicated to Green Algae. Mol Biol Evol 29:3625-3639 . https://doi.org/10.1093/molbev/mss178

Toth J, Ismaiel AA, Chen JS (1999) The ald gene, encoding a coenzyme A-acylating aldehyde dehydrogenase, distinguishes Clostridium beijerinckii and two other solvent-producing clostridia from Clostridium acetobutylicum. Appl Environ Microbiol 65:4973-4980

van Lis R, Baffert C, Couté Y, Nitschke W, Atteia A (2013) Chlamydomonas reinhardtii chloroplasts contain a homodimeric pyruvate: Ferredoxin oxidoreductase that functions with FDX1. Plant Physiol 161:57-71 . https://doi.org/10.1104/pp.112.208181

van Lis R, Brugière S, Baffert C, Couté Y, Nitschke W, Atteia A (2020) Hybrid cluster proteins in a photosynthetic microalga. FEBS J 287:721-735 . https://doi.org/10.1111/febs.15025

van Lis R, González-Halphen D, Atteia A (2005) Divergence of the mitochondrial electron transport chains from the green alga Chlamydomonas reinhardtii and its colorless close relative Polytomella sp. Biochim Biophys Acta 1708:23-34 . https://doi.org/10.1016/j.bbabio.2004.12.010

van Lis R, Mendoza-Hernández G, Groth G, Atteia A (2007) New insights into the unique structure of the F0F 1-ATP synthase from the chlamydomonad algae Polytomella sp. and Chlamydomonas reinhardtii. Plant Physiol 144:1190-1199 . https://doi.org/10.1104/pp.106.094060

van Lis R, Popek M, Couté Y, Kosta A, Drapier D, Nitschke W, Atteia A (2017) Concerted up-regulation of aldehyde/alcohol dehydrogenase (ADHE) and starch in Chlamydomonas reinhardtii increases survival under dark anoxia. J Biol Chem 292:2395-2410 . https://doi.org/10.1074/jbc.M116.766048

Wang D, Ning K, Li J, Hu J, Han D, Wang H, Zeng X, Jing X, Zhou Q, Su X, Chang X, Wang A, Wang W, Jia J, Wei L, Xin Y, Qiao Y, Huang R, Chen J, Han B, Yoon K, Hill RT, Zohar Y, Chen F, Hu Q, Xu J (2014) Nannochloropsis genomes reveal evolution of microalgal oleaginous traits. PLoS Genet 10:e1004094 . https://doi.org/10.1371/journal.pgen.1004094

Wessel D, Flügge UI (1984) A method for the quantitative recovery of protein in dilute solution in the presence of detergents and lipids. Anal Biochem 138:141-143 . https://doi.org/10.1016/0003-2697(84)90782-6

Wise DL (1955) Carbon Sources for Polytomella caeca. J Protozool 2:156-158 . https://doi.org/10.1111/j.15507408.1955.tb02416.x

Wise DL (1959) Carbon Nutrition and Metabolism of Polytomella caeca. J Protozool 6:19-23 . https://doi.org/10.1111/j.1550-7408.1959.tb03921.x

Wise DL (1968) Effects of Acetaldehyde on Growth and Biosynthesis in an Algal Flagellate Polytomella caeca. J Protozool 15:528-531 . https://doi.org/10.1111/j.1550-7408.1968.tb02169.x

Wise DL (1970) Effect of Acetaldehyde on Growth in Succinate Media and Labeling RNA with 14C Succinate in Polytomella caeca. J Protozool 17:1970

Wu T, Li L, Jiang X, Yang Y, Song Y, Chen L, Xu X, Shen Y, Gu Y (2019) Sequencing and comparative analysis of three Chlorella genomes provide insights into strain-specific adaptation to wastewater. Sci Rep 9:9514 . https://doi.org/10.1038/s41598-019-45511-6

Zimorski V, Martin WF (2014) Subcellular targeting of proteins and pathways during evolution. New Phytol 201:1-2 . https://doi.org/10.1111/nph.12566 
Table 1. Targeting predictions for Polytomella and C. reinhardtii ADHEs.

Predictions were made using four on-line localization predictors.

\begin{tabular}{|c|c|c|c|c|c|c|c|c|c|c|c|}
\hline \multirow[b]{3}{*}{ PSADHE1 } & \multicolumn{2}{|l|}{ MitoFate } & \multicolumn{3}{|l|}{ TargetP } & \multicolumn{3}{|c|}{ redotar v1.04 } & \multicolumn{3}{|c|}{ PredAlgo } \\
\hline & M probability & Cleavage site & M score & C score & Loc - RC & M score & C score & prediction & M score & C score & Target \\
\hline & 0.047 & nd & 0.047 & 0.882 & C. 2 & 0.07 & 0.34 & possibly $\mathrm{P}$ & 0.00861 & 0.890 & $c$ \\
\hline PsADHE2 & 0.991 & $25-26$ & 0.784 & 0.134 & $M-2$ & 0.7 & 0.06 & M & 0.0911 & 1.824 & c \\
\hline CrADHE1 & 0.017 & nd & 0.184 & 0.597 & $C \cdot 3$ & 0.49 & 0.49 & possiby $M$ & 0.0299 & 3.946 & c \\
\hline
\end{tabular}


Table 2. Enzymatic assays monitoring different activities of Polytomella sp. recombinant ADHEs.

The different reactions assessed are depicted in Figure 2. Enzymatic activities were determined spectrophotometrically following the production or consumption of NADH. Results are presented as the mean $+/$ - standard deviation of triplicate samples measured from three independent protein preparations. Note that the assays for reaction 1 were performed in absence of an iron chelator. Since acetaldehyde formed in reaction \#1 reacts away to ethanol immediately, and reactions \#1 and \#2 both produce NAD in a 1:1 stoichiometry, the real Vmax for reaction 1 can be extrapolated, corresponding to $50 \%$ to the determined Vmax.

\begin{tabular}{|c|c|c|c|c|c|}
\hline \multirow[b]{2}{*}{ Reaction } & \multirow[b]{2}{*}{ Substrates } & \multirow[b]{2}{*}{ Products } & \multicolumn{3}{|c|}{$V \max (\mu \mathrm{mol} . \mathrm{min}-1 . \mathrm{mg}-1)$} \\
\hline & & & rADHE1 & rADHE1_t & rADHE2 \\
\hline$\# 1$ & acetyl-CoA & $\begin{array}{l}\text { acetaldehyde, CoASH } \\
\text { (ethanol) }\end{array}$ & $1.88 \pm 0.0085$ & $2.221 \pm 0.096$ & $1.52 \pm 0.087$ \\
\hline$\# 2$ & acetaldehyde & ethanol & $2.095 \pm 0.171$ & $2.246 \pm 0.080$ & $0.0034 \pm 0.002$ \\
\hline$\# 3$ & ethanol & acetaldehyde & $2.887 \pm 0.257$ & $2.552 \pm 0.075$ & $0.0087 \pm 0.001$ \\
\hline \#4 & acetaldehyde, CoASH & acetyl-CoA & $0.271 \pm 0.0103$ & $0.619 \pm 0.073$ & $23.45 \pm 1.104$ \\
\hline
\end{tabular}

